\title{
Development of Reintroduction Techniques and Population Monitoring of Radiated Tortoises (Astrochelys radiata) in Southern Madagascar: Ampotaka: First Result for 3 Month Acclimatation
}

\author{
Soary Tahafe Randrianjafizanaka ${ }^{1}$, Rejo Fienena Felicity ${ }^{2}$, Lily-Arison Rene Roland ${ }^{2}$, \\ Herilala Randriamahazo ${ }^{3}$, Bernard Devaux ${ }^{4}$ \\ ${ }^{1}$ Department of Animal Biology, Faculty of Science, University of Toliara, Toliara, Madagascar \\ ${ }^{2}$ Department of Biological Sciences, Faculty of Science, University of Toliara, Toliara, Madagasca \\ ${ }^{3}$ Turtle Survival Alliance (TSA) Madagascar, Antananarivo, Madagascar \\ ${ }^{4}$ SOPTOM-Turtle Village, Gonfaron, France \\ Email: tahafinas@yahoo.fr, rejo felicite@yahoo.fr, lilyarirson@yahoo.fr, herilala@turtlesurvival.org
}

Received 25 July 2014; revised 4 September 2014; accepted 10 October 2014

Copyright (C) 2014 by authors and OALib.

This work is licensed under the Creative Commons Attribution International License (CC BY).

http://creativecommons.org/licenses/by/4.0/

(c) (i) Open Access

\section{Abstract}

The radiated tortoise (Astrochelys radiata) of Madagascar is critically endangered with extinction. The Turtle Survival Alliance (TSA) oversees the in-situ captive breeding program for this species and assesses the suitability of reintroduction from captivity as a management strategy is of great importance. 120 adult and juvenile animals from the quarantine center Mangily/Ifaty $(30 \mathrm{~km}$ north of Toliara) and 24 resident animals from Ampotaka and Tranovaho will be selected in the implementation of the research on the best strategy reintroduction Astrochelys radiata in southern Madagascar, by a soft release of six months and one year (where animals are acclimated to the release site for a pre-determined period) and hard-release. Finally, 90 individuals were destined for a soft release (45 for six months and 45 for one year), 30 individuals for hard release and 24 animals resident population as controls. On 21 January 2014, the first group of 45 animals was transferred to Ampotaka for 1 year of acclimatization. The other 45 will be transferred to the 2 nd pen and the latest wave of 30 individuals will be transferred in January 2015. All animals will be radio-tagged and monitored from January 2015 to May 2015. Actually, short-term success will be assessed by investigating survival and pre-release response in body mass, movement and microhabitat use. All 45 reintroduce tortoise survived the duration of this study, remained in pen of pre-release/release and used habitat and resources in a similar way to wild tortoises.

How to cite this paper: Randrianjafizanaka, S.T., Felicity, R.F., Roland, L.-A.R., Randriamahazo, H. and Devaux, B. (2014) Development of Reintroduction Techniques and Population Monitoring of Radiated Tortoises (Astrochelys radiata) in Southern Madagascar: Ampotaka: First Result for 3 Month Acclimatation. Open Access Library Journal, 1: e394.

http://dx.doi.org/10.4236/oalib.1100394 


\title{
Keywords
}

\section{Astrochelys radiata, Acclimatization}

\author{
Subject Areas: Environmental Sciences
}

\section{Introduction}

An efficient long-term post-release monitoring strategy is therefore fundamental to any evaluation of a tortoise translocation or reintroduction. However, in reality, the success of such interventions is mainly only ever evaluated in the short-term. Post-release survival, movement, fidelity to release site, resource use, fitness, reproduction, behavior and social interactions are all variables that might be investigated in an assessment of short-term success [1]-[3]. In our case, we investigate how 45 captive-bred radiated tortoises which are pre-released three months earlier have responded to their acclimatation to provide an evaluation of the short-term success of this reintroduction project. Do they survive in the pen? Do pre-released tortoises gain or lose condition? Do they exploit resources in a similar comportment to wild tortoises?

We know that the site of pre-releasing experimental reintroduction must provide a suitable habitat which must be large enough to ensure dispersion and food. The size of the habitat is 1 ha. Specifically, the desired goal of the first phase is to prepare a partial balance sheet and anticipated future results to estimate temporal variations of travel, know the vital area of each turtle and highlight the relationship of the values with different explanatory variables (gender, seasonal...) or understand the habitat use for each period of the annual cycle of the species and identify the preferred habitat. All these elements will appreciate the adaptation of the Astrochelys radiata capabilities that ensure its survival, survival and reproduction in the new range and the long-term improvement of knowledge will also better integrate ecological requirements of the species in the future reintroduction. But we are now at the results of three months after the transfer. Collected data show that the tortoises are well and alive.

\section{Materials and Methods}

\subsection{Selection of Individual}

We select and isolate animals (juveniles, adults) of quarantine center Mangily/Ifaty. And to avoid possible loss or mortality during the acclimatization phase, an additional 30 animals (10 males +10 juveniles +10 females) were included in more than 90 (soft 60 and hard 30) required for scientific validity. Thus, the total number of people transferring Mangily/Ifaty is 120, distributed as follows: for the first wave to acclimate for 1 year (soft release), 45 animals will be selected, including 15 juveniles $+15+$ males and 15 females transferred in January 2014 and released in January 2015.

\subsection{Acclimatation}

The tortoises released in this study were all bred at the sacred forest in Sirempo; all tortoises experienced different captive conditions they were kept in 1ha of pen rearing enclosures. They have no feeding occurred food and water .Individuals selected for release had size that would ensure that risk from predation was minimal and at a developmental stage that would optimize resistance to environmental factors (e.g. climate and food availability) without compromising their potential to settle within the area of release [4]. All individuals were at the juvenile/adult stage of development. Data collection will be done by filling out the scorecard, distributed according to the phases of research, such as; 1 month acclimation weekly monitoring of animals and the state of the enclosure; during the acclimatization: monthly monitoring of animals and enclosures states.

\subsection{Floristic Inventory in Each Enclosure}

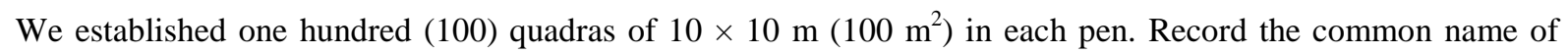
each plant food and phonology (flowers, fruits, leaves), heights and diameters only for plants having a diameter and a height of more than $2.5 \mathrm{~cm}$. we evaluate the habitat quality by recording the parameters characterizing the 
micro-habitat (substrate type, size, shade), vegetation (vegetation, soil, medium trees, vegetation type, abundance/dominance) and the specific temperature and humidity (iButton set at four corner of the compound and the data will be collected every six hours/month for six months). This inventory have been taken before the arrival of turtles in pens (zero state factory); will also perform during the rain (to find out if there are new varieties rate of plant regeneration plants ) and finally after releasing (check the percentage of consumed plants).

\subsection{Body Mass}

To determine the physical condition of the animal introduced during the adaptation phase, fortnightly visits pens are and will be made and morphometric data of individuals are recorded and six variables were taken into account for each species: Weight a precision balance, the two pairs of variables: length (CL), width (CW) and height (HT) dorsal carapace length (PL) and width of faceplate (CW), using caliper.

\subsection{Habitat Use}

Mapping with a GPS map of the reintroduction area, the boundary of the sacred forest, places raketa conduit, open places. Note also physical abnormalities [5], and where the tortoise was observed: the number of quadrats, habitat type, time, the percentage of forest cover and soil behavior (digging, sleep, eat, mate, lay...) the location and temperature and humidity geo-referencing are collected. (See description of identification). Feces are also sample confirm the diet, but need veterinary support for further analysis of the components.

\section{Results}

\subsection{Selection of Individual}

The tortoises were all sexually mature and had carapace lengths of 360.4 - 76, $7 \pm 01 \mathrm{~mm}$ and body masses of $8000-310 \pm 01 \mathrm{~g} /$. Sex was determined by secondary sex characteristics [6]. A rigorous health screening and behavioral examination was undertaken to ensure that all turtles were healthy and to reduce the risk of spreading diseases, we trait them by Levamisole (mg) dosage $20 \mathrm{mg} / \mathrm{kg}$, Levamisole $5 \%$ injected on SQ (ml). The turtles were individually and permanently marked by marginal notching. Measurements of the 45 selected for yearlings (01 year) acclimation Ampotaka (Table 1).

\subsection{Pen Floristic Inventory}

The site of pre-releasing experimental reintroduction must provide a suitable habitat must be large enough to ensure dispersion and food where the size of 1 ha. Specifically, the desired goal of the first phase and to prepare a partial balance sheet and anticipated future results such estimate temporal variations of travel, know the vital area of each turtle and highlight the relationship of the values it one with different explanatory variables (gender, seasonal...) or understand the habitat use for each period of the annual cycle of the species and identify the habitat preferred. All these elements will appreciate the adaptation of the Astrochelys radiata capabilities that ensure its survival, and reproduction in the new range and long-term improvement of knowledge will also better integrate ecological requirements of the species in the future reintroduction. But we are now at the results of three months after the transfer of tortoises and collect donated can already say that the tortoises are all well and alive.

Floristic surveys conducted in both enclosed gave us the table below, families and species will be completed as and its availability (Table 2).

\subsection{Body Mass}

All tortoises pre-released in January 2014 survived and had no apparent serious negative reaction in their adaptation without they and no health problems were encountered. The hard release tortoises released in 2011 also continued to survive and growth normally without incident throughout the duration of this study. Tortoises were and weren't provided food and constant access to drinking water. Tortoises were weighed monthly during acclimatation (Table 3).

During these three months of acclimatization, we notice slight variations in animal weight $100 \mathrm{~g}$ to $200 \mathrm{~g}$ located if some win 100 to $200 \mathrm{~g}$ else lose; adults were most stressed their new lifestyle, while juveniles do not have all suffered and otherwise $100 \%$ gained weight. 
S. T. Randrianjafizanaka et al.

Table 1. Morphometric data transferred to Sirempo turtles.

\begin{tabular}{|c|c|c|c|c|c|c|c|c|c|c|}
\hline Site & Tort ID & Ifaty ID & Sex & CL & PL & PW & Height & Weight & $\begin{array}{l}\text { Levamisole (mg) } \\
\text { dosage } 20 \mathrm{mg} / \mathrm{kg}\end{array}$ & $\begin{array}{c}\text { Levamisole 5\% } \\
\text { injected on SQ (ml) }\end{array}$ \\
\hline Ampotaka & 5131 & 1143 & M & 334 & 324 & 205 & 194 & 6500 & 130 & 2.6 \\
\hline Ampotaka & 818 & 188 & M & 325 & 311 & 205 & 198 & 6800 & 136 & 2.7 \\
\hline Ampotaka & 517 & 7501 & M & 317 & 291 & 213 & 174 & 6750 & 135 & 2.7 \\
\hline Ampotaka & 702 & 2700 & M? & 300 & 289 & 197 & 163 & 5000 & 100 & 2.0 \\
\hline Ampotaka & 411 & 1401 & M & 312 & 298 & 199 & 174 & 6000 & 120 & 2.4 \\
\hline Ampotaka & 808 & 881 & M & 302 & 287 & 190 & 175 & 5500 & 110 & 2.2 \\
\hline Ampotaka & 5320 & 352 & M & 304 & 275 & 182 & 184 & 5800 & 116 & 2.3 \\
\hline Ampotaka & 511 & 151 & M & 346 & 316 & 219 & 199 & 8500 & 170 & 3.4 \\
\hline Ampotaka & 2030 & 23 & M & 326 & 301 & 194 & 194 & 6500 & 130 & 2.6 \\
\hline Ampotaka & 817 & 7801 & M & 329 & 301 & 213 & 196 & 6750 & 135 & 2.7 \\
\hline Ampotaka & 510 & 150 & M & 334 & 310 & 213 & 203 & 8250 & 165 & 3.3 \\
\hline Ampotaka & 400 & 400 & M & 361 & 331 & 219 & 197 & 8000 & 160 & 3.2 \\
\hline Ampotaka & 4854 & 4840 & M & 324 & 305 & 192 & 187 & 7000 & 140 & 2.8 \\
\hline Ampotaka & 4420 & 442 & M & 325 & 291 & 208 & 207 & 7000 & 140 & 2.8 \\
\hline Ampotaka & 6480 & 468 & M & 354 & 323 & 217 & 197 & 8250 & 165 & 3.3 \\
\hline Ampotaka & 305 & 35 & $\mathrm{~F}$ & 363 & 341 & 235 & 208 & 8500 & 170 & 3.4 \\
\hline Ampotaka & 5181 & 111 & $\mathrm{~F}$ & 309 & 287 & 189 & 189 & 6250 & 125 & 2.5 \\
\hline Ampotaka & 6090 & 69 & $\mathrm{~F}$ & 290 & 272 & 183 & 170 & 5600 & 112 & 2.2 \\
\hline Ampotaka & 604 & 4600 & F & 309 & 285 & 193 & 184 & 6400 & 128 & 2.6 \\
\hline Ampotaka & 1450 & 415 & F & 285 & 279 & 173 & 183 & 5000 & 100 & 2.0 \\
\hline Ampotaka & 2060 & 26 & F & 310 & 295 & 177 & 189 & 5600 & 112 & 2.2 \\
\hline Ampotaka & 3400 & 430 & $\mathrm{~F}$ & 303 & 281 & 195 & 189 & 6250 & 125 & 2.5 \\
\hline Ampotaka & 2440 & 424 & $\mathrm{~F}$ & 324 & 305 & 197 & 186 & 6750 & 135 & 2.7 \\
\hline Ampotaka & 603 & 3600 & $\mathrm{~F}$ & 326 & 301 & 201 & 202 & 7250 & 145 & 2.9 \\
\hline Ampotaka & 3 & 3 & $\mathrm{~F}$ & 345 & 327 & 210 & 184 & 8000 & 160 & 3.2 \\
\hline Ampotaka & 2080 & 28 & $\mathrm{~F}$ & 314 & 295 & 183 & 186 & 5250 & 105 & 2.1 \\
\hline Ampotaka & 109 & 9100 & $\mathrm{~F}$ & 345 & 313 & 211 & 185 & 8250 & 165 & 3.3 \\
\hline Ampotaka & 1141 & 1114 & $\mathrm{~F}$ & 324 & 286 & 191 & 194 & 7150 & 143 & 2.9 \\
\hline Ampotaka & 206 & 6200 & $\mathrm{~F}$ & 317 & 282 & 202 & 196 & 6500 & 130 & 2.6 \\
\hline Ampotaka & 107 & 171 & $\mathrm{~F}$ & 314 & 283 & 192 & 173 & 6000 & 120 & 2.4 \\
\hline Ampotaka & 6901 & 1960 & Juv & 118.8 & & & & 380 & 8 & 0.8 \\
\hline Ampotaka & 4961 & 1946 & Juv & 115.2 & & & & 340 & 7 & 0.7 \\
\hline Ampotaka & 8022 & 2082 & Juv & 121.8 & & & & 400 & 8 & 0.8 \\
\hline Ampotaka & 8851 & 1885 & Juv & 112.4 & & & & 340 & 7 & 0.7 \\
\hline Ampotaka & 991 & 1909 & Juv & 125.2 & & & & 410 & 8 & 0.8 \\
\hline Ampotaka & 22 & 2002 & Juv & 112.9 & & & & 320 & 6 & 0.6 \\
\hline Ampotaka & 2012 & 2021 & Juv & 114.7 & & & & 310 & 6 & 0.6 \\
\hline Ampotaka & 8931 & 1583 & Juv & 120.5 & & & & 400 & 8 & 0.8 \\
\hline Ampotaka & 6231 & 1263 & Juv & 117.4 & & & & 380 & 8 & 0.8 \\
\hline Ampotaka & 9991 & 1999 & Juv & 117.2 & & & & 330 & 7 & 0.7 \\
\hline Ampotaka & 52 & 2005 & Juv & 117.8 & & & & 320 & 6 & 0.6 \\
\hline Ampotaka & 4002 & 2040 & Juv & 116.3 & & & & 390 & 8 & 0.8 \\
\hline Ampotaka & 8991 & 1989 & Juv & 108.4 & & & & 310 & 6 & 0.6 \\
\hline Ampotaka & 5981 & 1958 & Juv & 115.0 & & & & 300 & 6 & 0.6 \\
\hline Ampotaka & 9132 & 2193 & Juv & 117.2 & & & & 330 & 7 & 0.7 \\
\hline
\end{tabular}


Table 2. Floristic inventories enclosure 1 and 2.

\begin{tabular}{|c|c|c|c|c|c|c|c|c|c|c|c|c|c|c|c|}
\hline Localisation & Local name & Growth type & & & & & & & Ind & & & & & & \\
\hline Pen $1 \& 2$ & Atratra & Tree & + & + & + & + & + & + & + & + & + & + & + & + & + \\
\hline Pen $1 \& 2$ & Aride & Tree & + & & & & & & & & & & & & \\
\hline Pen $1 \& 2$ & Alokatala & Herb & + & + & & & & & & & & & & & \\
\hline Pen $1 \& 2$ & Avoha & Tree & + & & & & & & & & & & & & \\
\hline Pen $1 \& 2$ & Balabaky & Tree & + & & & & & & & & & & & & \\
\hline Pen 1\&2 & Berondroke & Tree & + & & & & & & & & & & & & \\
\hline Pen 1\&2 & Daro & Tree & + & & & & & & & & & & & & \\
\hline Pen $1 \& 2$ & Darovy & Tree & + & + & + & + & & & & & & & & & \\
\hline Pen 1\&2 & Famata & Tree & + & + & + & + & + & + & + & + & + & & & & \\
\hline Pen $1 \& 2$ & Fandrivotse & Herb & + & + & & & & & & & & & & & \\
\hline Pen $1 \& 2$ & Fatikakanga & Tree & + & + & & & & & & & & & & & \\
\hline Pen $1 \& 2$ & Feka & Tree & + & + & + & + & + & + & + & & & & & & \\
\hline Pen $1 \& 2$ & Fipio & Tree & + & & & & & & & & & & & & \\
\hline Pen $1 \& 2$ & Fivikakanga & Tree & + & + & + & + & & & & & & & & & \\
\hline Pen $1 \& 2$ & Halimboro & Tree & + & & & & & & & & & & & & \\
\hline Pen 1\&2 & Hazovy & Tree & + & + & & & & & & & & & & & \\
\hline Pen $1 \& 2$ & Hazofoty & Tree & + & & & & & & & & & & & & \\
\hline Pen $1 \& 2$ & Hazonta & Tree & + & & & & & & & & & & & & \\
\hline Pen $1 \& 2$ & Jabihy & Tree & + & + & + & & & & & & & & & & \\
\hline Pen 1\&2 & Kamanga & Tree & + & & & & & & & & & & & & \\
\hline Pen $1 \& 2$ & Kapaipoty & Tree & + & + & + & & & & & & & & & & \\
\hline Pen 1\&2 & Katrafay & Tree & + & + & + & & & & & & & & & & \\
\hline Pen $1 \& 2$ & Kotake & Herb & + & + & + & + & & & & & & & & & \\
\hline Pen $1 \& 2$ & Kirava & Tree & + & & & & & & & & & & & & \\
\hline Pen $1 \& 2$ & Longonaky & Tree & & & & & & & & & & & & & \\
\hline Pen $1 \& 2$ & Malaignevotse & Herb & + & + & + & + & + & + & + & & & & & & \\
\hline Pen 1\&2 & Mendoravy & Tree & + & + & & & & & & & & & & & \\
\hline Pen $1 \& 2$ & Monongo & Tree & + & & & & & & & & & & & & \\
\hline Pen 1\&2 & Raketa & Tree & + & + & + & + & & & & & & & & & \\
\hline Pen $1 \& 2$ & Rohondroho & Tree & + & + & + & + & + & + & + & + & + & + & & & \\
\hline Pen 1\&2 & Somangy & Tree & + & & & & & & & & & & & & \\
\hline Pen $1 \& 2$ & Taly & Tree & + & + & & & & & & & & & & & \\
\hline Pen 1\&2 & Tsingena & Tree & + & & & & & & & & & & & & \\
\hline Pen $1 \& 2$ & Tainankanga & Herb & + & & & & & & & & & & & & \\
\hline Pen $1 \& 2$ & Vaovy & Tree & + & & & & & & & & & & & & \\
\hline Pen 1\&2 & Vaha & Tree & + & & & & & & & & & & & & \\
\hline Pen $1 \& 2$ & Voambiry & Tree & + & & & & & & & & & & & & \\
\hline Pen $1 \& 2$ & Vahomtsoy & Tree & + & & & & & & & & & & & & \\
\hline Pen $1 \& 2$ & Vohipindy & Tree & + & & & & & & & & & & & & \\
\hline Pen $1 \& 2$ & Vontaky & Tree & + & & & & & & & & & & & & \\
\hline
\end{tabular}


Adult body mass (BM) for reintroduce tortoise at time of May 2014 (9650 kg, $4400 \mathrm{~kg}$ ) was lower than their body mass in January 2014 (10.250 kg - 5 kg) for adult, for juvenile they all win weight (340 g - $400 \mathrm{~g}$ ) in January to $(380 \mathrm{~g}-515 \mathrm{~g})$ in Mars. Body mass fluctuated for individuals during the first 3 month period. However, as can be seen in adult only 5 of the 20 tortoises gained in mass, whilst 4 showed no net gain and 10 declined in bosy mass. All juvenile tortoises show a gain in BM during the first three months of acclimatation (Figure 1).

\subsection{Habitat Use}

Composition and habitat quality has a significant effect on vital field of establishment [6] and to understand how high captive tortoises exploit their habitat is important in assessing their adaptation to their new environment [7]. Analysis of habitat use is also essential to assess the relevance of the release site [8]. The main natural habitat turtle is considered the forests, fields, open place a succulent plant, but they are not restricted to this habitat [9]. The acclimatization pens contains these different habitats and what is their use, tortoises often use open the enclosure parts and semi-open areas.

Microhabitat of each pen is sub-divided into four categories including:

- Ala sariky (where trees and shrubs are fairly spaced).

- Ala kitiky (where the vegetation is so dense and tight that we cannot even enter).

- Liolio or moka (places containing no tree but only litter.

- Ala Kibo (places not containing trees but lower vegetation $40 \mathrm{~cm}$.

And during those three months of acclimatization 45 individuals are finding in major part in open place (ala Kibo, ala sariky,) are found in some tight places (ala tery or ala kitiky).

In terms of behavior, the maximum activity (walking, eating) is between $7 \mathrm{~h}$ and $9 \mathrm{~h}$ in the morning against beyond this time, the animals rest (resting) on everything that can provide the shade (trees, underbrush, dead wood) as the temperature increases more and more (Figure 2).

\section{Conclusion}

The first three months have given fairly positive results in the adaptations of animals especially juveniles. Acclimatization has not yet completed. We can show the evolution of this phase because for this case it is still too early to conclude an event which determines guidelines on the reintroduction. Actually, the first group of 45

Table 3. Demographic picture of gains and weight loss animal.

\begin{tabular}{cccc}
\hline & Weight loss & Weight win & Total \\
\hline 15 Males & 14 & 1 & \\
15 Females & 10 & 5 & \\
15 Juveniles & 0 & 15 & 45 \\
\hline
\end{tabular}

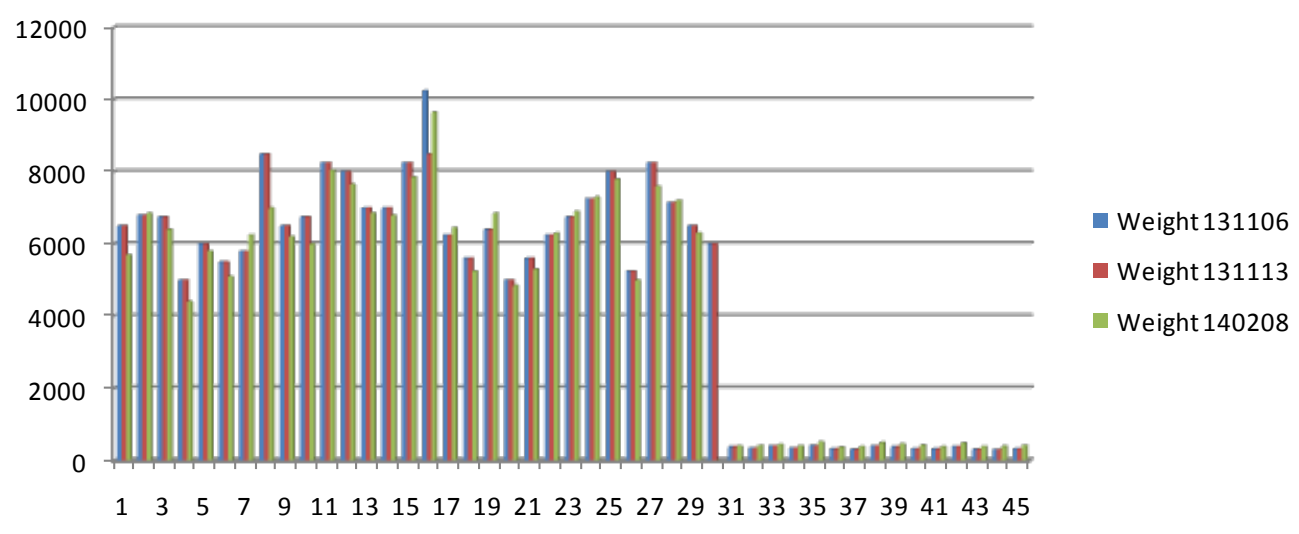

Figure 1. Variation of the individual weights of each tortoise. 


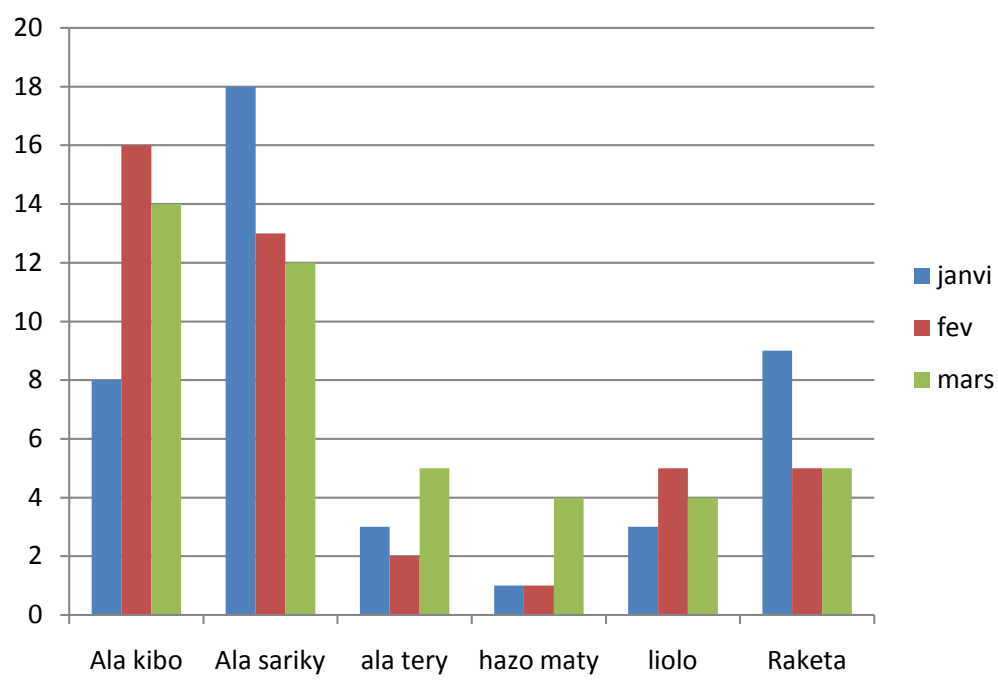

Figure 2. Demographic preferential microhabitat.

animals is in their 3th month of acclimatization and the second group of other 45 tortoises is preparing for leaving the quarantine center mangily to reach the 2nd pen for the second six months of acclimatization in July. During this mission, our future work will transfer and follow the 2nd group of 45 individuals (including 15 males, 15 females and 15 juveniles) and continue the study of space utilization resident species and tortoise acclimation for 1 year.

\section{References}

[1] Griffith, B., Scott, J.M., Carpenter, J.W. and Reed, C. (1989) Translocation as a Species Conservation Tool: Status and Strategy. Science, 245, 477-480. http://dx.doi.org/10.1126/science.245.4917.477

[2] Gibbons, J.W. (1986) Movement Patterns among Turtle Populations: Applicability to Management of the Desert Tortoise. Herpetologica, 42, 104-113.

[3] Germano, J.M. and Bishop, P.J. (2008) Suitability of Amphibians and Reptiles for Translocation. http://www.iucnredlist.org/details/9016/0/full.

[4] Pedrodo, M. and Sarovy, A. (2000) Trial Release of the World's Rarest Tortoise Geochelone yniphora in Madagascar. Biological Conservation, 95, 333-342.

[5] Homer, J.B. (1998) Why We Iterate: Scientific Modeling in Theory and Practice. System Dynamics Review, 12, 1-19.

[6] Ernst, C.H., Lovich, J.E. and Barbour, R.W. (1994) Turtles of the United States and Canada. Smithsonian Institution, Washington DC.

[7] Reid, D., Durrell, L. and Rakotebearison, G. (1989) The Captive Breeding Project for the Angonoka. Geochelone yniphora, in Madagascar. Dodo, 34-48.

[8] Riedle, J.D., Averill-Murray, R.C., Lutz, C.L. and Bolen, D.K. (2008) Habitat Use by Desert Tortoises (Gopherus agassizii) on Alluvial Fans in the Sonoran Desert, South-Central Arizona. Copeia, 414-420.

[9] Juvik, J.O., Keister, A.R., Reid, D., Coblentz, B. and Hoffman, J. (1997) The Conservation Biology of the Angonoka, Geochelone yniphora, in Northwestern Madagascar: Progress Report. In: Van Abbema, J., Ed., Proceedings: Conservation, Restoration and Management of Tortoises and Tortoises-An International Conference, New York Turtle and Tortoise Society and the WCS Turtle Recovery Program, New York, 345-350. 